\title{
Detection of homodimer formation of CD99 through extracelluar domain using bimolecular fluorescence complementation analysis
}

\author{
Gowoon Choi ${ }^{1 *}$, Sang Wook Lee ${ }^{2 *}$, \\ Kyoung Cheon Jung ${ }^{3}$ and Eun Young Choi ${ }^{1,2,4}$ \\ ${ }^{1}$ Interdisciplinary Graduate Program in Genetic Engineering \\ Seoul National University \\ Seoul 110-799, Korea \\ ${ }^{2}$ Graduate Program of Immunology \\ ${ }^{3}$ Department of Pathology \\ Seoul National University College of Medicine \\ Seoul 110-799, Korea \\ ${ }^{4}$ Corresponding author: Tel, 82-2-740-8530; \\ Fax, 82-2-740-8538; E-mail, eycii@snu.ac.kr \\ *These authors contributed equally to this work.
}

Accepted 18 October 2007

Abbreviations: $\mathrm{BiFC}$, bimolecular fluorescence complementation assay; GFP, green fluorescent protein; hCD4, human CD4; mCD99, mouse CD99; PILR, paired immunoglobulin-like receptor; VN and VC, $\mathrm{N}$ and $\mathrm{C}$ terminal halves of venus (modified GFP), respectively, used for BiFC

\begin{abstract}
Although various functions of CD99 have been reported, such as apoptosis and homotypic aggregation of thymocyte and transendothelial migration of immune cells, biochemical/molecular natures of CD99 are still elusive. Using mouse CD99 gene, we show that CD99 forms homodimer through its extracellular domain. Expression of mouse CD99 is up-regulated on $T$ cells after CD3-mediated activation, like the case for human CD99. The potential of CD99 to form homodimer was tested with a recently developed bimoleular fluorescence complementation analysis (BiFC). In BiFC analysis, the dimerization-induced fluorescence was strong near the perinuclear region and was faded at the cell membrane. However, surface expression of CD99 was still detected by flow cytometry, suggesting that CD99 either in monomer form or in association with other molecules exists on the cell surface. In BiFC analysis using CD99 mutants with its extracellular, transmembrane, or cytosolic domains changed to corresponding human CD4 domains, the mutant replaced with human CD4-extracellular domain did not produce fluorescence. Purified soluble CD99-Fc fusion pro-
\end{abstract}

teins bound to CD99-Fc immobilized onto the gold sensor chip in surface plasmon resonance analysis, confirming that the extracellular domain was responsible for dimer formation. Intracytoplasmic staining for CD99 expression in the thymocytes and mature T cells showed that most of the cells, even the cells with low surface level of CD99, contained the molecule inside the cell. Our results suggest that majority of CD99 homodimers may exit in the cell and be exported to the cell surface, dissociating from each other, after a certain regulatory signal is delivered.

Keywords: CD99 antigen, mouse; dimerization; microscopy, fluorescence; protein transport; T-lymphocytes

\section{Introduction}

CD99 is a cell surface glycoprotein leukocyte antigen that does not belong to any of the known protein families. It is broadly distributed in many tissues, particularly human cortical thymocytes (Dworzak et al., 1994), Ewing sarcoma cells, and peripheral primitive neuroectodermal tumors (Ambros et al., 1991; Fellinger et al., 1991; Lumadue et al., 1994; Lee et al., 2003a), and has been implicated in various functions, including cell adhesion (Bernard et al., 1995, 2000; Kasinrerk et al., 2000), apoptosis of thymocytes (Bernard et al., 1997) and Ewing sarcoma cells (Sohn et al., 1998; Cerisano et al., 2004), and T cell activation (Oh et al., 2007). CD99 is also involved in the intracellular transport of surface molecules, such as the $T$ cell receptor complex (TCR) and MHC II proteins (Choi et al., 1998; Yoon et al., 2003). CD99 is expressed on endothelial cells and treatment with a mAb against CD99 arrests the transmigration of monocytes through a monolayer of cultured endothelial cells (Schenkel et al., 2002). A close relationship between the down-regulation of CD99 expression and the generation of Hodgkin and Reed-Sternberg cells in Hodgkin's lymphoma has been investigated (Kim et al., 1998, 2000; Lee et al., 2001, 2003b) and this has drawn interest to the molecular mechanism of CD99 expression.

Despite these accumulated data on the functions of CD99, the biochemical and molecular 
nature of the molecule has not been well defined. The gene encoding CD99 is located in the pseudoautosomal region of the $\mathrm{Y}$ chromosome (Smith et al., 1993; Ross et al., 2003). The murine ortholog of human CD99 has been cloned (Park et al., 2005). Whether the cloned gene is a functional ortholog of the human CD99 molecule has been studied in terms of the transmigration of T lymphocytes to inflamed skin (Schenkel et al., 2002). Recently, paired immunoglobulin-like receptor (PILR) has been identified as the natural ligand of CD99 (Shiratori et al., 2004; Wilson et al., 2006). The ligation of mouse CD99 (mCD99) to PILR induces apoptosis in immature thymocytes (manuscript in preparation). It is possible that CD99 might form homodimers, because bands near 45 and 60 $\mathrm{kDa}$ are detected in western blots under nonreducing conditions in lysates from human thymocytes (unpublished finding). However, this issue has not been clarified.

Several methods have been developed to investigate protein interactions, including yeast two hybrid system and co-immunoprecipitation. In this study, we used a recently developed technique, bimolecular fluorescence complementation (BiFC), to determine whether mouse CD99 forms dimers and to study their cellular localization. BiFC technique uses the two non-fluorescent halves of a green fluorescent protein (GFP) variant tagged to two proteins. The binding of the two fusion proteins leads to the reconstitution of the GFP variant, which then produces fluorescence. This technique has been used to successfully dissect interactions between cytokine receptors, cytochromes and transcription factors (Aparicio et al., 2006; Citovsky et al., 2006; Shyu et al., 2006; Yano et al., 2006; Dong et al., 2007)

In this study, we used the mouse ortholog of the CD99 gene and BiFC analysis. The results indicate that mCD99 dimerization occurs in the cellular context. The dimer was localized to the nuclear membrane, endoplasmic reticulum (ER) and Golgi apparatus, collectively, the perinuclear region. This study might be useful for further studies of mCD99 function.

\section{Materials and Methods}

\section{Cloning of expression vectors}

The previously cloned mCD99 (Park et al., 2005) was subcloned into pCMV-VN and pCMV-VC vectors, provided by Dr. Chang-Deng $\mathrm{Hu}$ (Purdue University). To produce soluble proteins, expression constructs for PILR-Fc, mCD99-Fc and human CD4-Fc were made by amplifying the extra- cellular portion of the corresponding cDNA sequence by $\mathrm{PCR}$, and then subcloning them inframe into the $\mathrm{pCl}$-neo expression vector containing an N-terminal human IgG4 Fc domain tag. These expression vectors were transfected into 293T cells and the culture supernatants were subjected to protein $G$ column chromatography (Amershambiosciences, Piscataway, NJ) to purify the fusion proteins.

\section{Transfection and BIFC analysis by fluorescence microscopy}

The 293T or COS7 cells were cultured in DMEM containing $5 \%$ FBS and were transfected using the calcium phosphate method. Cells were observed under a fluorescence microscope $48 \mathrm{~h}$ after transfection and digital micrographs were obtained (Axiovert 25C: Carl Zeiss, Germany). For DAPI staining, cells were washed free of medium using PBS and were fixed with $1 \%$ paraformaldehyde in PBS for $20 \mathrm{~min}$, followed by washing and resuspension in $0.1 \%$ saporin in PBS. DAPI was added to the cells at the concentration recommended by the manufacturer.

\section{T cell activation}

$\mathrm{T}$ cells were purified from the spleen of C57BL/6 (B6) mice by magnetic cell sorting (MACs) using anti-CD4 (Gk1.5) microbeads according to the manufacturer's instructions (Miltenybiotech, Auburn, CA). In a 24-well plate, the $1 \times 10^{6}$ purified CD4 T cells were stimulated in the presence of irradiated (2000 cGy) $3 \times 10^{6}$ B6 splenocytes and anti-mouse CD3 $\mathrm{mAb}(1 \mu \mathrm{g} / \mathrm{ml})$. On days 1,3 , and 5 after activation, the CD4 T cells were subjected to flow cytometry to determine mCD99 expression on the cell surface.

\section{Western blotting of transfected cells}

Transfected 293T cells were lysed for $30 \mathrm{~min}$ at $4^{\circ} \mathrm{C}$ in RIPA buffer (50 mM Tris, pH 7.4, $150 \mathrm{mM}$ $\mathrm{NaCl}, 1 \%$ Nonidet $\mathrm{P} 40,5 \mu \mathrm{g} / \mathrm{ml}$ leupeptin) and centrifuged at $15,000 \mathrm{rpm}$ at $4^{\circ} \mathrm{C}$. The lysates were resolved on $12 \%$ SDS-PAGE gels and subjected to western blotting using an antibody against a mycepitope (9E10; Santa Cruz Biotechnology, Santa Cruz, CA) and an HRP-conjugated goat anti-rat antibody (Dako, Carpinteria, CA).

\section{Flow cytometry}

Transfected 293 T or COS7 cells were incubated at $4^{\circ} \mathrm{C}$ for $30 \mathrm{~min}$ in staining buffer $(1 \times$ PBS with $0.1 \%$ BSA and $0.1 \%$ sodium azide) containing a 
PE-conjugated anti-mCD99 mAb (EJ2). Activated mouse CD4 $\mathrm{T}$ cells and mouse splenocytes and thymocytes were stained with staining buffer containing PE-conjugated EJ2 with APC-conjugated anti-mouse CD4 and FITC-conjugated anti-mouse CD44 mAbs, or with APC-conjugated anti-mouse CD8 and FITC-conjugated anti-mouse CD4 mAbs, respectively. Fluorescence-conjugated mAbs were purchased from BD Biosciences Pharmingen (San Diego, CA), except for the PE-conjugated EJ2 antibody (Dinona Inc., Seoul, Korea). For intracytoplasmic staining, mouse thymocytes and splenocytes were fixed with $1 \%$ paraformaldehyde, washed, and stained with same combination of antibodies in the presence of $0.5 \%$ saporin. After staining, cells were washed twice with $1 \times$ PBS and once with FACS buffer $(1 \times$ PBS with $0.1 \%$ BSA and $0.1 \%$ sodium azide). Stained cells were analyzed using a FACSCalibur equipped with CellQuest software (BD Biosciences Pharmingen).

\section{Surface plasmon resonance analysis}

A CM5-gold chip sensor was assembled and docked in the BIACORE instrument (Biacore 2000 System, Biacore AB, Sweden). It was subjected to sequential preclearing, washing, and activating steps using solutions provided by the manufacturer. The mCD99-Fc was flowed over the activated surface at a rate of $5 \mu \mathrm{l} / \mathrm{min}$ and a concentration of $100 \mu \mathrm{g} / \mathrm{ml}$. To eliminate potential noncovalent interactions between mCD99-Fc molecules, a washing procedure was preformed using a glycine- $\mathrm{HCl}$ buffer ( $\mathrm{pH}=3.0,2.5,2.0$ sequentially). Analyte solutions consisting of PILR-Fc, mCD99$\mathrm{Fc}$, and human CD4-Fc in HEPES-EP buffer (20 $\mu \mathrm{g} / \mathrm{ml}$; Biacore $A B$ ) were flowed at $5 \mu \mathrm{l} / \mathrm{min}$ over the mCD99-Fc-immobilized on the sensor chip.

\section{Results}

\section{The cloned mouse CD99 gene is the functional ortholog of human CD99}

The surface expression of human CD99 molecule is up-regulated after activation (Oh et al., 2007). To test whether the mouse ortholog of the CD99 gene showed a similar pattern, we examined the expression profile of mCD99 on T cells stimulated via CD3. On days 1,3 , and 5 post-stimulation, $T$ cells were tested for activation using anti-CD44 mAb and for surface expression of CD99. As time passed after stimulation, CD4 $\mathrm{T}$ cells were activated, with increased expression of CD44 on the cell surface. CD99 expression was very low on T cells before activation, but increased on activated cells from day 1 post-activation, was up- regulated to a high level at day 3 , and decreased by day 5 (Figure 1). Thus the mCD99 gene that we used was the functional homolog of human CD99.

\section{Detection of CD99-dimer formation in BiFC analysis}

The possibility of dimer formation by CD99 was suggested following the detection of a band with an apparent size of $60 \mathrm{kDa}$ in western blots of human thymocytes under non-reducing conditions (unpublished finding): however, this possibility has remained unresolved. Therefore, we used the recently developed $\mathrm{BiFC}$ technique and tested the potential of mCD99 to form homodimers. To analyze the dimerization potential of mCD99 in the cellular context, we first constructed separate vectors for the expression of mCD99 tagged with the $\mathrm{N}$ - and C-terminal halves of GFP (abbreviated as $\mathrm{VN}$ and $\mathrm{VC}$, respectively). We also made another vector for the expression of human CD4 fused with VC (hCD4-VC). The expression of the fusion proteins of the predicted sizes was verified by western blots of the transfected cells using $\mathrm{mAb}$ against the myc-tag epitope that was attached to the $\mathrm{N}$-terminal end of the extracellular domain of CD99 (Figure 2A).

We then performed BiFC analysis in COS7 cells, which were chosen for their large cell surface area and also because the localization of fluorescence is somewhat easier in these cells than in 293T cells. To determine whether mCD99 would dimerize in the cellular context, we transfected COS7 cells with the mCD99-VC and mCD99-VN vectors or with $\mathrm{mCD} 99-\mathrm{VC}$ and $\mathrm{hCD} 4-\mathrm{VC}$ vectors (negative control). When observed under the fluorescence microscope $48 \mathrm{~h}$ later, COS 7 cells cotransfected with mCD99-VC and mCD99-VN vectors exhibited bright fluorescence, which was localized predominantly in the perinuclear region (Figure 2B). This localization was confirmed by DAPI staining. This pattern was different from that observed in COS-7 cells co-transfected with Jun$\mathrm{VN}$ and Fos-VC, which interact with each other in the nucleus ( $\mathrm{Hu}$ et al., 2002; Hu and Kerppola, 2003). No fluorescence was detected in the negative control that was co-transfected with mCD99$\mathrm{VN}$ and hCD4-VC vectors.

To measure the fluorescence induced by mCD99-dimerization and its membrane expression, we performed flow cytometry on the cotransfected $\operatorname{COS} 7$ cells using a $\mathrm{PE}$-conjugated anti-mCD99 mAb, by which BiFC-induced green fluorescence and surface expression of CD99 could be detected separately in the FL1 and FL2 channels, respectively. FACS results indicated that 

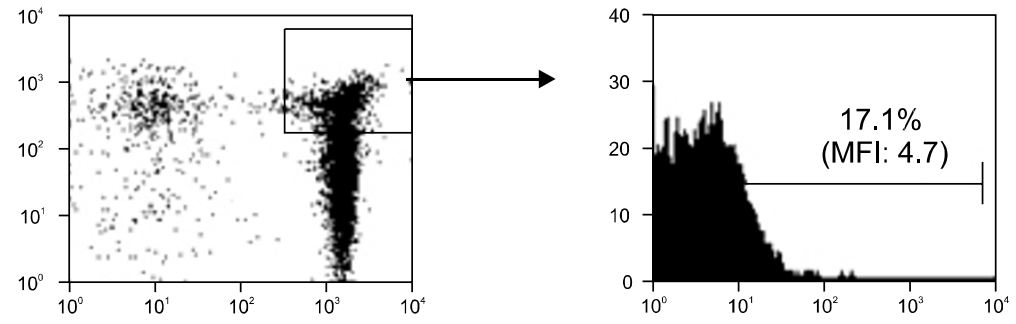

Day 0
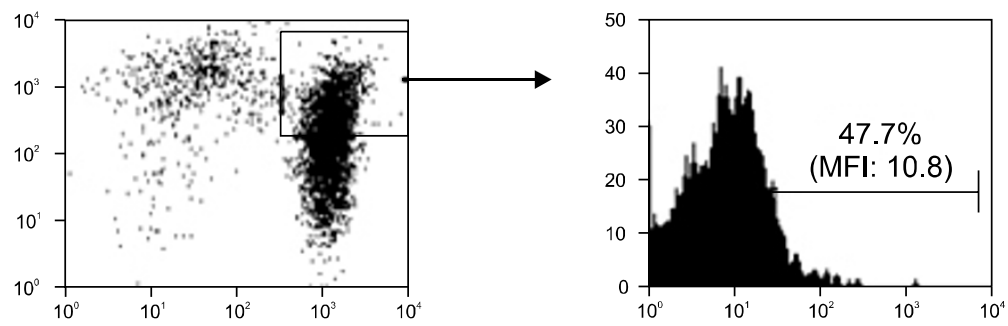

Day 1
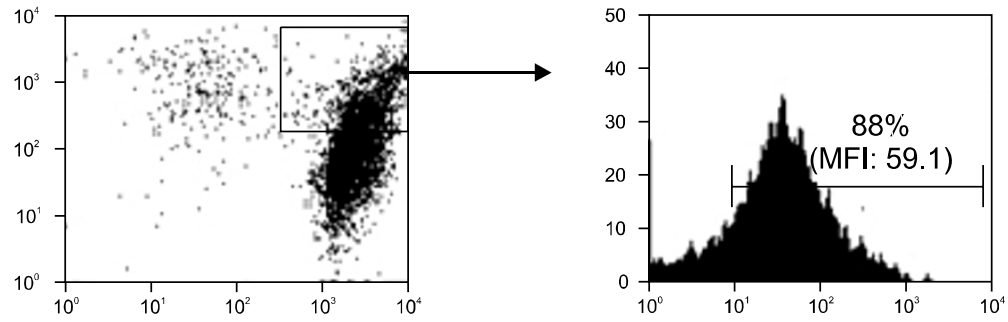

Day 3

Figure 1. The expression of $m C D 99$ was up-regulated after $\mathrm{T}$ cell activation. CD4 T cells $\left(1 \times 10^{6}\right)$ purified from the spleen of normal mice were stimulated with anti-CD3 mAb $(1 \mu \mathrm{g} / \mathrm{ml})$ in the presence of irradiated feeder splenocytes for 1 week. On days 1,3 and 5 after activation, the $T$ cells in the culture were stained with PE-conjugated anti-mCD99

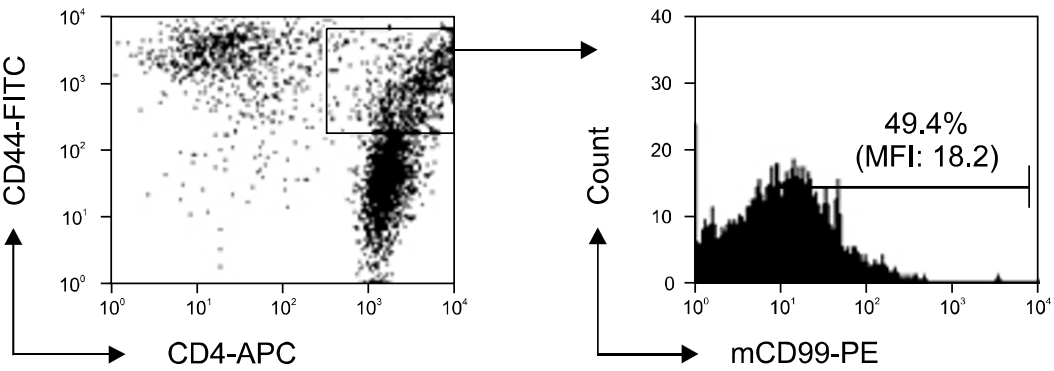

Day 5 mAb (EJ2), FITC-conjugated anti-mouse $\mathrm{CD} 44 \mathrm{mAb}$ and APC-conjugated anti-mouse CD4 mAb. The percentages of the cells positive for CD99 staining in the activated $T$ cells are indicated by mean fluorescence intensity (MFI) values in parentheses.

cells that exhibited BiFC-derived GFP fluorescence as a result of mCD99 dimerization were also positive for membrane-bound mCD99 staining (Figure $2 \mathrm{C}$ ). This was somewhat unexpected, because GFP fluorescence in the co-transfected cells was rarely observed on the plasma membrane in BiFC analysis (Figure 2B), and indicated that mCD99 molecules did dimerize in intracellular compartments such as the ER and Golgi, but might exist as monomers or in association with other molecules at the plasma membrane.

\section{CD99 forms homodimers through the extracellular domain}

The dimerization of CD99 suggested the presence of a homotypic binding domain within the protein.
To investigate this possibility, we constructed expression vectors for chimeric molecules in which the extracellular, transmembrane and cytoplasmic domains of CD99 were replaced by the corresponding domains of human CD4, and fused with VC. The constructs for the mutant proteins (Ext mutant, TM mutant, and Cyt mutant) were named Mut-Ext-VC, Mut-TM-VC, and Mut-Cyt-VC, respectively. Each of these chimeric vectors was cotransfected into COS7 cells with mCD99-VN, and the cells were observed for BiFC fluorescence $48 \mathrm{~h}$ later. Although cells transfected with Mut-TM-VC and mCD99-VN vectors or with Mut-Cyt-VC and mCD99-VN vectors produced fluorescence, cells transfected with Mut-Ext-VC and mCD99-VN vectors did not, indicating that a homotypic binding domain existed within the extracellular portion of 
A

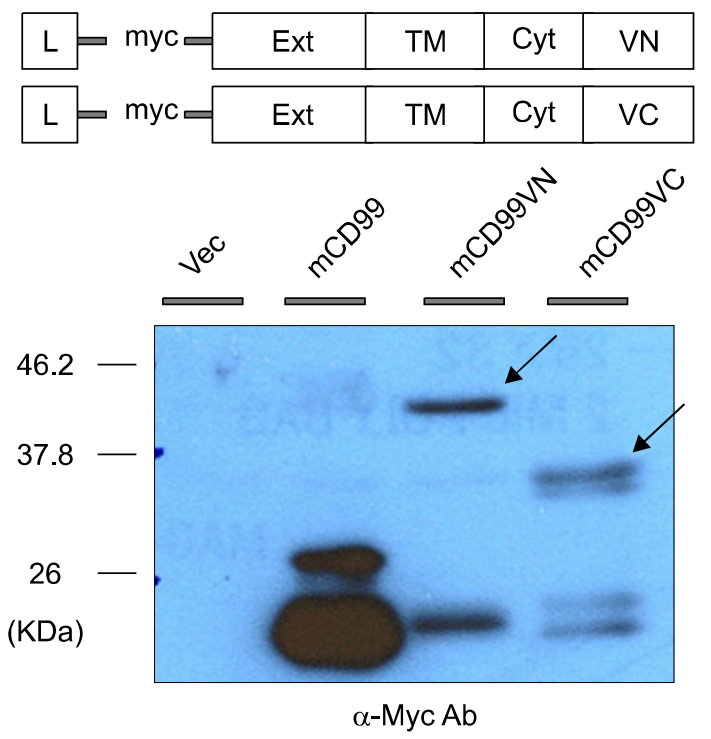

C mCD99-VN + mCD99-VC mCD99-VN + hCD4-VC
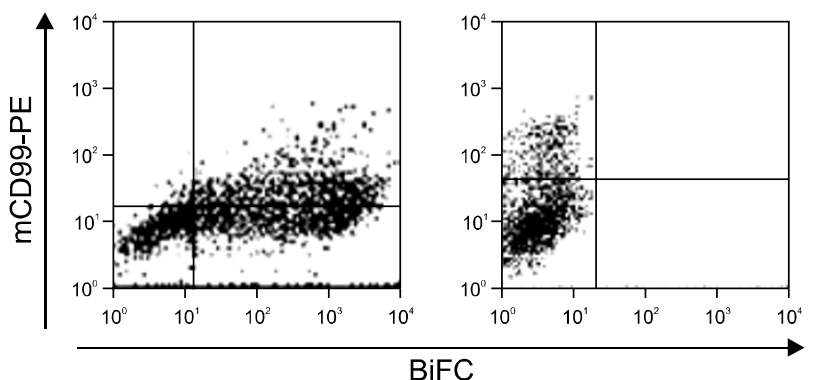

B
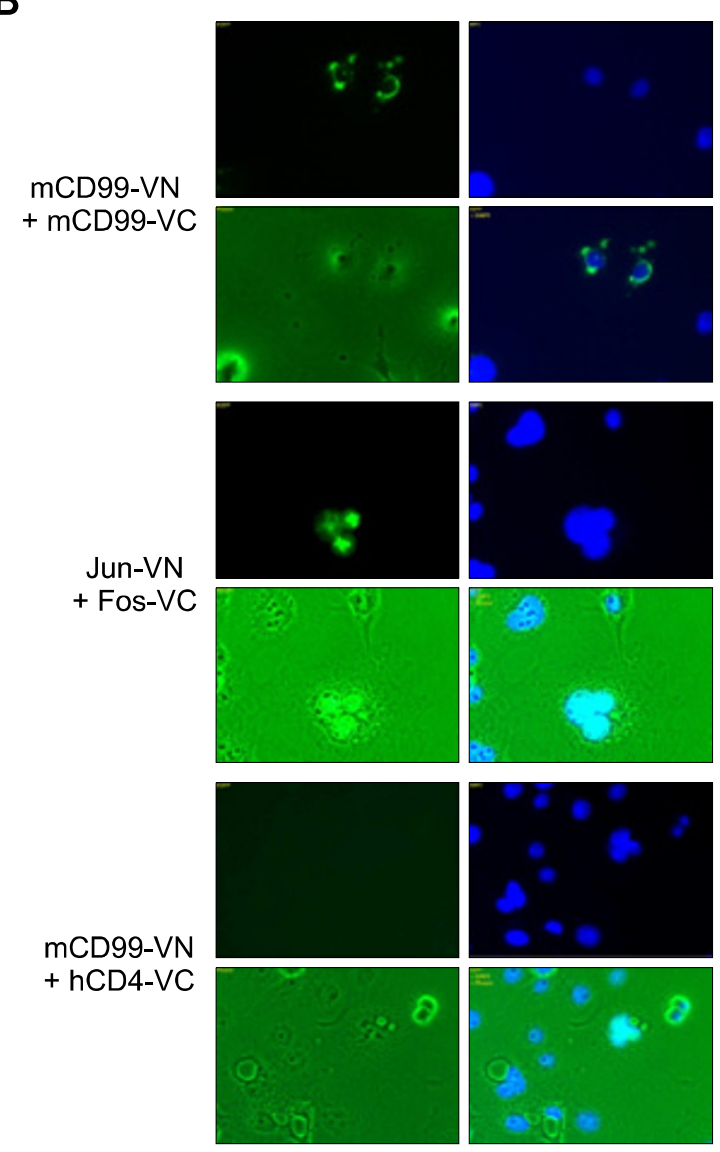

BiFC

Figure 2. Formation of mCD99 homodimers in BiFC analysis. (A) Diagram of DNA constructs for the expression of mCD99 fused with VN or VC at the $\mathrm{C}$-terminus and tagged with a myc-epitope at the $\mathrm{N}$-terminial end of the extracellular domain. Each construct was transfected into $293 \mathrm{~T}$ cells. The expression of fusion proteins of the predicted molecular sizes was confirmed by western blots. Wild-type CD99 tagged with a myc-epitope was included for size indication as a positive control. (B) COS7 cells were co-transfected with mCD99-VN and mCD99-VC. The hCD4-VC construct was transfected with mCD99-VN as a negative control DNA constructs for Fos-VC and Jun-VN were co-transfected as a positive control. Cells were fixed, stained with DAPI (blue), and observed under fluorescence microscopy $48 \mathrm{~h}$ after transfection. Green fluorescence indicated the formation of dimers. Representative pictures taken at $400 \times$ magnification are shown. (C) At $48 \mathrm{~h}$ after transfection, COS7 cells transfected with the described constructs were surface-stained with PE-conjugated EJ2. The two-color FACS results show the BiFC (x-axis) and surface expression ( $y$-axis) of mCD99. The results are representative of more than five independent experiments.

mCD99 (Figure 3A). However, the cellular BiFC location of heterodimers formed between wild-type mCD99 and Mut-TM or Mut-Cyt mutants was different from that of the dimers formed between wild-type mCD99 molecules. Whereas BiFC fluorescence caused by the dimerization of wild-type mCD99 was predominantly restricted within the perinuclear region (Figure 2B), the dimers that formed between wild-type mCD99 and two mutant CD99 proteins, the TM and Cyt mutants, exhibited widespread BiFC fluorescence in addition to that at the plasma membrane (Figure $3 \mathrm{~A}$ ). This suggests that export of CD99 molecules to the cell mem- brane may be regulated through the transmembrane and cytosolic domains of the molecule. FACS analysis verified that cells that were cotransfected with the wild-type mCD99 VN and Mut-Ext-VC vectors failed to produce fluorescence, but did show surface expression of CD99 (Figure 3B).

\section{Direct binding of the extracellular CD99 domain to the CD99 extracellular domain}

We used surface plasmon resonance (SPR) analysis to confirm the BiFC result that indicated that 
A
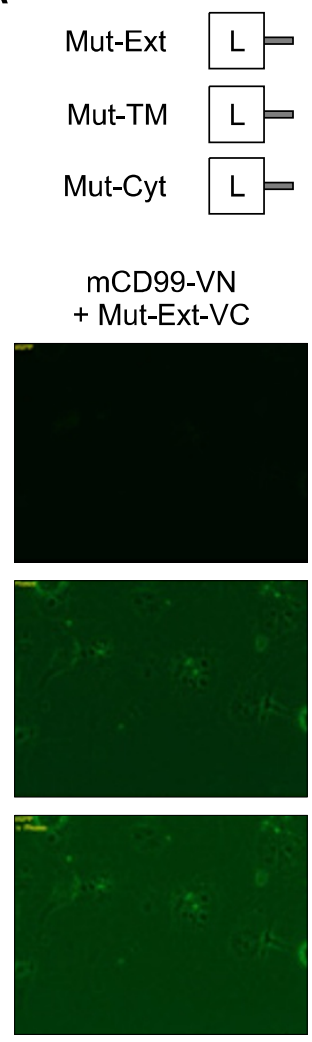

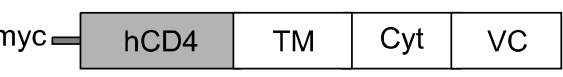

\begin{tabular}{cc|c|c|c|}
\cline { 2 - 2 } & Ext & hCD4 & Cyt & VC \\
\cline { 2 - 5 } & Ext & TM & hCD4 & VC \\
\hline
\end{tabular}
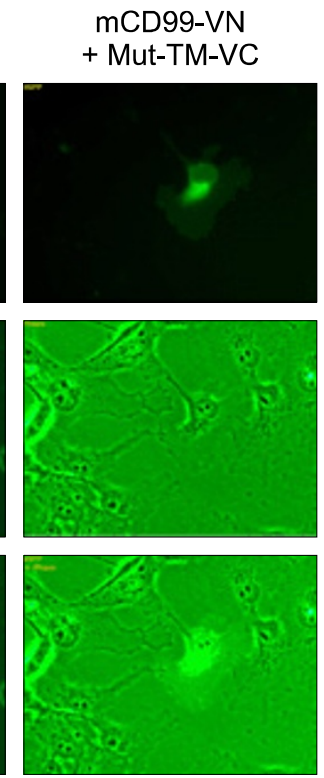

mCD99-VN

+ Mut-Cyt-VC
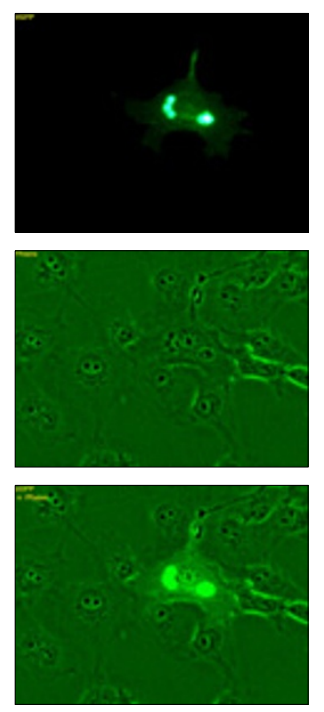

B

mCD99-VN + Mut-Ext-VC

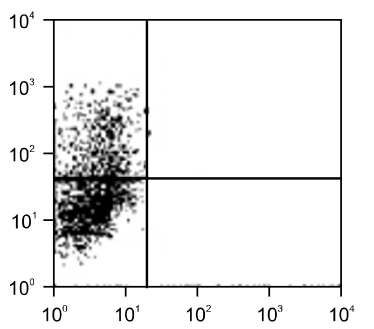

mCD99-VN + Mut-TM-VC

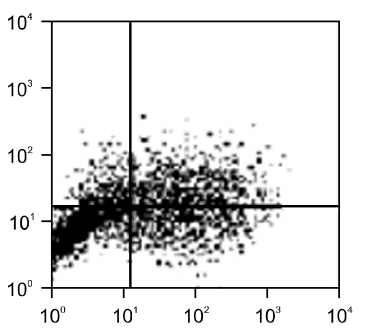

mCD99-VN + Mut-Cyt-VC

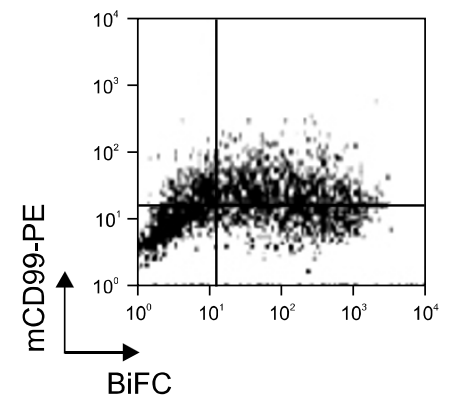

Figure 3. Formation of mCD99 through extracellular domains in BiFC. (A) Vectors were constructed for expression of mutants of mCD99 in which the extracellular (Mut-Ext), transmembrane (Mut-TM), or cytoplasmic (Mut-Cyt) domains were replaced by the corresponding domains from the hCD4 molecule. VC vectors for each mutant were co-transfected with mCD99-VN. COS7 cells were observed under fluorescence microscopy $48 \mathrm{~h}$ after transfection to detect BiFC-induced emission of green fluorescence (400 $\times$ magnification). (B) Transfected COS7 cells were subjected to FACS analysis for the surface expression of $\mathrm{mCD} 99$.

CD99 dimerization was mediated through the extracellular domain. The mCD99-Fc, a fusion molecule consisting of the extracellular domain of mCD99 and the Fc domain of human IgG4 was immobilized on CM5-coated gold chips. PILR-FC (positive control), mCD99-Fc, and hCD4-Fc (negative control) diluted to $20 \mu \mathrm{g} / \mathrm{ml}$ in HEPES buffer were then injected over the gold surface. As expected, PILR-Fc, a natural ligand for mCD99 (Shiratori et al., 2004) and mCD99-Fc bound stably to the surface with approximately 300 resonance units (RU) and $400 \mathrm{RU}$, respectively (Figure 4), but the binding of hCD4-Fc was negligible (approximately $50 \mathrm{RU}$ ). This confirms that the extracellular domain of CD99 is the binding domain for homodimer formation.

\section{CD99 molecules are present in the cells, even when the surface expression is low}

The results obtained from the $\mathrm{BiFC}$ and flow cytometric analyses suggested the possibility that surface levels of mCD99 might be different from the intracellular amounts of the molecule. To evaluate this idea, we performed flow cytometry using mouse thymocytes and spleen cells, which represent different developmental stages of cells with different surface levels of CD99. Surface staining of mouse thymocytes with anti-mCD99 mAb demonstrated that there were differences in surface CD99 expression according to thymocyte development, with down-regulated surface expression on single positive cells (Figure 5A). The surface level 

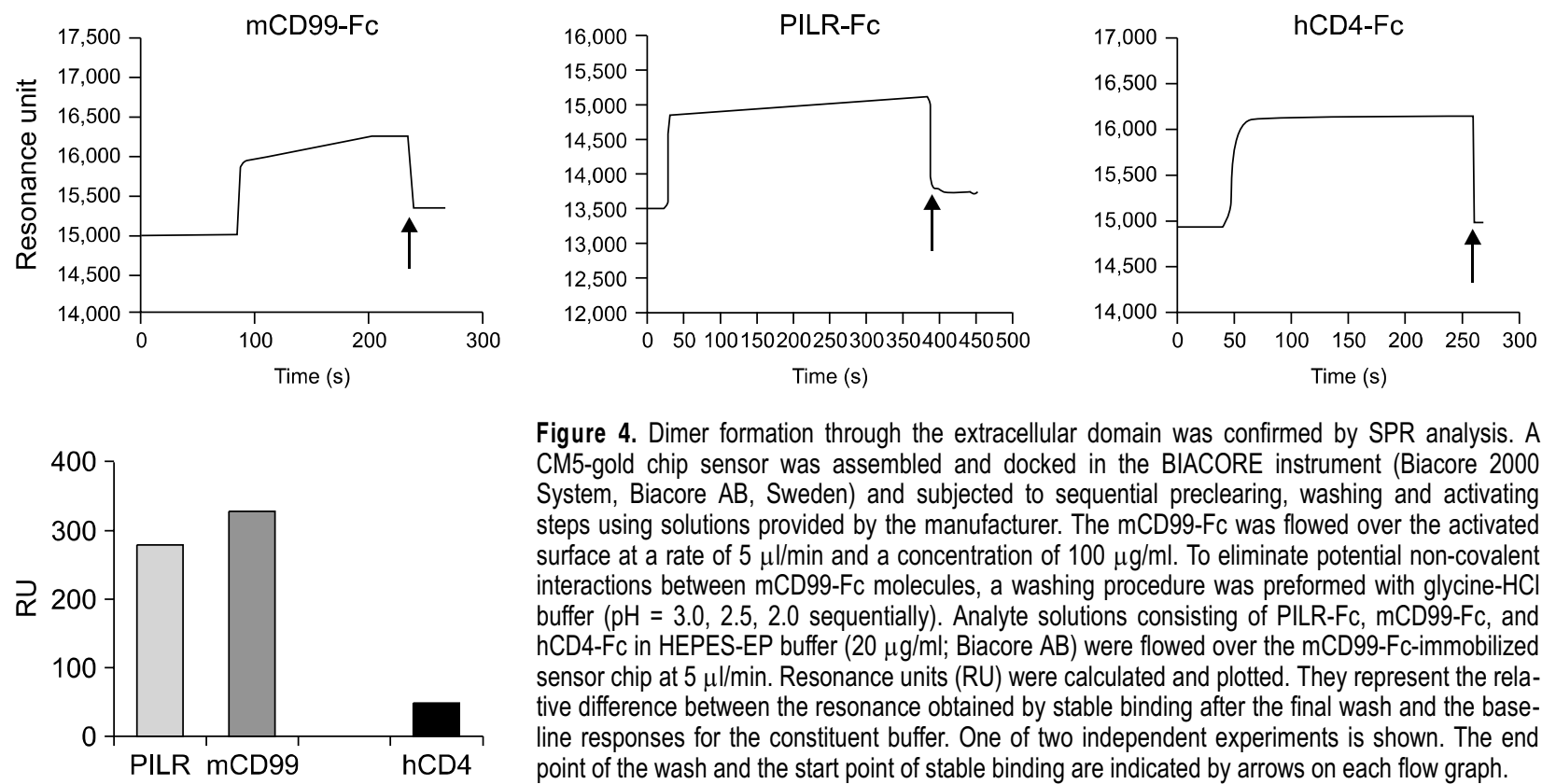

Figure 4. Dimer formation through the extracellular domain was confirmed by SPR analysis. A CM5-gold chip sensor was assembled and docked in the BIACORE instrument (Biacore 2000 System, Biacore $A B$, Sweden) and subjected to sequential preclearing, washing and activating steps using solutions provided by the manufacturer. The mCD99-Fc was flowed over the activated surface at a rate of $5 \mu \mathrm{l} / \mathrm{min}$ and a concentration of $100 \mu \mathrm{g} / \mathrm{ml}$. To eliminate potential non-covalent interactions between $\mathrm{mCD} 99-\mathrm{Fc}$ molecules, a washing procedure was preformed with glycine- $\mathrm{HCl}$ buffer ( $\mathrm{pH}=3.0,2.5,2.0$ sequentially). Analyte solutions consisting of PILR-Fc, mCD99-Fc, and hCD4-Fc in HEPES-EP buffer $(20 \mu \mathrm{g} / \mathrm{ml}$; Biacore AB) were flowed over the mCD99-Fc-immobilized sensor chip at $5 \mu \mathrm{l} / \mathrm{min}$. Resonance units (RU) were calculated and plotted. They represent the relative difference between the resonance obtained by stable binding after the final wash and the baseline responses for the constituent buffer. One of two independent experiments is shown. The end point of the wash and the start point of stable binding are indicated by arrows on each flow graph.

A

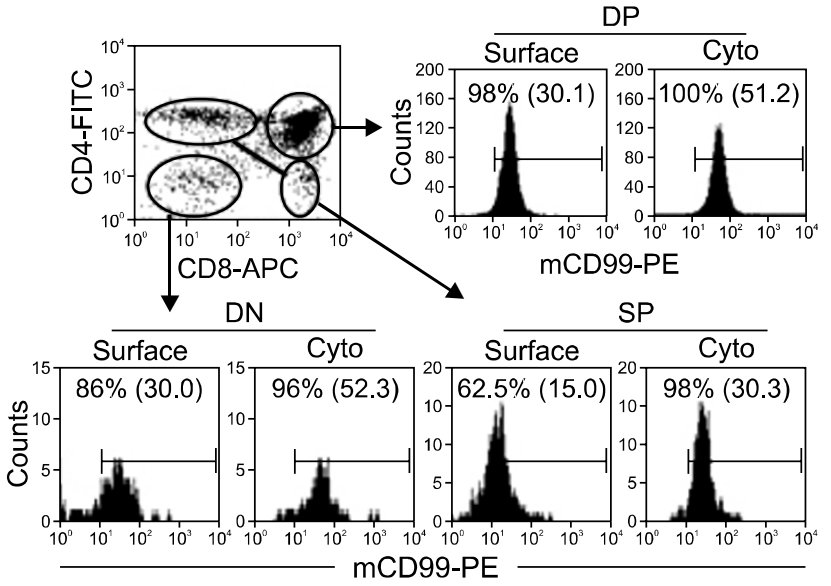

B

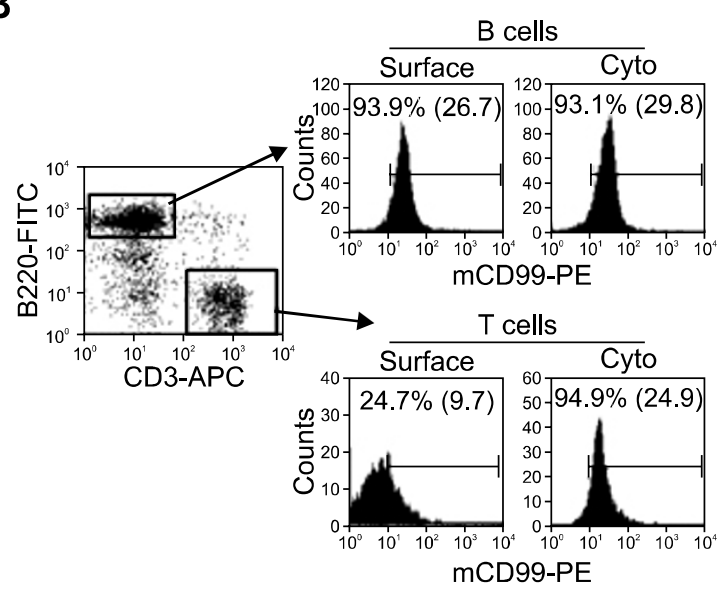

Figure 5. Comparison of surface and intracytoplasmic levels of $m C D 99$ on thymocytes and splenocytes. Suspensions of mouse thymocytes $(A)$ and splenocytes (B) were surface-stained with a combination of PE-conjugated EJ2, APC-conjugated anti-mCD8, and FITC-conjugated anti-mCD4 mAbs (A) or with a combination of PE-conjugated EJ2, APC-conjugated anti-mCD3, and FITC-conjugated anti-mB220 mAbs (B). To perform intracytoplasmic staining, cells were fixed with $1 \%$ paraformaldehyde and stained with the same combination of antibodies in the presence of $0.5 \%$ saporin. The percentages of cells positive for CD99 expression are indicated in the single histograms, with MFI values in parentheses. The figures are representatives of three independent experiments.

was further decreased on mature and naive T cells in the spleen (Figure 5B). However, when total CD99 molecules both inside and outside of the cells were stained, almost all cells from the different stages showed positive binding to antimCD99 Ab. These differences in surface and total levels of CD99 expression by T cells was in con- trast to the stable levels of CD99 in and on mature $B$ cells (Figure 5B). These results demonstrate that CD99 molecules are present in the cells even when the surface level is down-regulated, suggesting that export to the cell membrane may be controlled by signals related to $T$ cell differentiation. 


\section{Discussion}

We produced several lines of evidence that mCD99 exists in a dimeric form in the cellular context and that the extracellular domain is critical for dimer formation between CD99 molecules.

Dimer formation has been reported in many proteins, with the involvement of different domains in the molecular interactions. In the case of the $T$ cell receptor (TCR)-CD3 complex, the oligomerization of each component is crucial for the transport of the complex to the cell surface. In this complex, the $\mathrm{CD} 3 \zeta$ protein exists as a $\mathrm{CD} 3 \zeta-\zeta$ homodimer that functions in intracytoplasmic signal transduction. The dimerization occurs via interaction between aspartic acid residues located in the transmembrane domain (Call and Wucherpfennig, 2004). CD8 (Bonneville and Lang, 2002), IL-3 receptor (Stomski et al., 1996) and $\mathrm{m} 3$ muscarinic receptor (Zeng and Wess, 1999) molecules form disulfide-linked dimers on the cell surface. The dimers can be formed either during the maturation of the protein in the ER and Golgi or after arriving at the cell surface. CD4 is an example of a receptor that dimerizes after arriving at the cell surface and the dimerization occurs via a disulfide bond in the second extracellular domain (Maekawa et al., 2006). The neonatal Fc receptor (FcRn), which is involved in immunoglobulin metabolism (Roopenian et al., 2003), is non-covalently associated with $\beta 2$-microglobulin $(\beta 2 \mathrm{~m})$. In a $\beta 2 \mathrm{~m}$-null cell line, FcRn forms homodimers by pairing cysteins within the external domain, and the disulfide-bonded oligomers localize in the ER, suggesting that the $\beta 2 m$ association with $F c R n$ is important to exit the ER and move to endosomes and the cell surface (Zhu et al., 2002). In this respect, it cannot be ruled out that the homodimers between mCD99 molecules detected in the ER and Golgi are transient molecules in the midst of the process of maturation and transport to the cell surface. The fact that the CD99-CD99 homodimers were localized predominantly near the perinuclear region, but heterodimers formed between wild-type mCD99 and TM or Cyt mutants were distributed to the cell membrane suggests that transport to the cell surface may require the dissociation of mCD99 from each other and/or association with other molecules. The transmembrane and/or cytoplasmic domains may provide a site for possible interaction with other molecules. According to an analysis of the CD99 amino acid sequence, there is no cystein residue that would allow disulfide-bond formation between CD99 molecules, and the cytoplasmic domain of CD99 is short, without any significant signaling motif. This indicates that possible associations of
CD99 with other molecules can deliver intracellular signals. Further studies, including point mutation analyses, will be required to clarify the nature of CD99 dimer formation.

Despite the low amino acid homology between human and mouse CD99 molecules (Park et al., 2005), the functional homology in terms of involvement in extravasation through endothelial cells is conserved (Bixel et al., 2004; Petri and Bixel, 2006). The mechanism by which CD99 participates in leukocyte extravasation is unknown. Our results suggest that homophilic interactions between CD99 on leukocytes and endothelial cells may be a candidate mechanism for diapedesis of lymphocytes through endothelial cells. However, Bixel et al. (2004) observed neither the direct binding of cells expressing mCD99 to mCD99-Fc nor any inhibition of lymphocyte transmigration by mCD99Fc treatment. Thus, they ruled out the possibility of homophilic interaction by CD99 being the mechanism of diapedesis through an endothelial layer. We also failed to detect any positive cells after staining with mCD99-Fc. However, we did detect extracellular domain-mediated CD99-Fc/CD99-Fc binding in the SPR analysis. The reason may be that we washed the microchip coated with CD99Fc under harsh conditions (low $\mathrm{pH}$ ) to eliminate pre-formed CD99-Fc dimers. Thus, in this regard, the BiFC technique is a unique method by which it was possible to detect the dimerization of mCD99 in the cellular context.

Our BiFC and FACS results revealed that even though the expression of mCD99 was low and down-regulated on $T$ cell surfaces, the molecules were contained within the cells. These results suggest that mCD99 molecules are present in the cells as a kind of reservoir, probably in homodimer form, and their transport to the cell surface is regulated according to $T$ cell differentiation or other cellular needs, as is the case for the up-regulation of TCR and MHC molecules after thymocyte engagement with mAbs to human CD99 (Choi et al., 1998). We were unable to perform western blots with ex vivo mouse thymocytes or T cells to detect bands corresponding to CD99 homodimers because of the lack of a mAb that recognizes CD99 on western blots with high affinity. Currently, we presume that, on the requirement for the upregulation of the surface expression of mCD99 immediately after the delivery of a signal, the transport of pre-existing molecules will immediately supplement the first wave of mCD99 molecules destined to the cell surface, followed by the second wave of protein by way of de novo synthesis, as reported in the cases of FasL expression by cytotoxic T cells (He and Ostergaard, 2007) and 
CTLA expression by activated T cells (Valk et al., 2006).

In conclusion, mCD99 forms a homodimer via its extracellular domain. Further studies of the biochemical and molecular characteristics of mCD99 and the identification of signal molecules related to CD99 function and expression are needed to understand the mechanism of CD99 involvement in the transmigration of lymphocytes.

\section{Acknowledgements}

We thank to Dr. Chang-Deng Hu (Purdue University) for providing plasmids encoding Venus $\mathrm{N}-173$ and Venus C-155 for BiFC analysis, and to Dr. Seong Hoe Park for helpful discussions. This work was supported by a Molecular and Cellular BioDiscovery Research Program (2007-03619) grant from the Ministry of Science and Technology, South Korea.

\section{References}

Ambros IM, Ambros PF, Strehl S, Kovar H, Gadner H, Salzer-Kuntschik M. MIC2 is a specific marker for Ewing's sarcoma and peripheral primitive neuroectodermal tumors. Evidence for a common histogenesis of Ewing's sarcoma and peripheral primitive neuroectodermal tumors from MIC2 expression and specific chromosome aberration. Cancer 1991;67:1886-93

Aparicio F, Sanchez-Navarro JA, Pallas V. In vitro and in vivo mapping of the Prunus necrotic ringspot virus coat protein C-terminal dimerization domain by bimolecular fluorescence complementation. J Gen Virol 2006;87:1745-50

Bernard G, Zoccola D, Deckert M, Breittmayer JP, Aussel C, Bernard A. The E2 molecule (CD99) specifically triggers homotypic aggregation of CD4+ CD8+ thymocytes. J Immunol 1995;154:26-32

Bernard G, Breittmayer JP, de Matteis M, Trampont $P$, Hofman P, Senik A, Bernard A. Apoptosis of immature thymocytes mediated by E2/CD99. J Immunol 1997;158: 2543-50

Bernard G, Raimondi V, Alberti I, Pourtein M, Widjenes J, Ticchioni M, Bernard A. CD99 (E2) up-regulates alpha4beta1-dependent $T$ cell adhesion to inflamed vascular endothelium under flow conditions. Eur J Immunol 2000;30: 3061-5

Bixel G, Kloep S, Butz S, Petri B, Engelhardt B, Vestweber D. Mouse CD99 participates in T-cell recruitment into inflamed skin. Blood 2004;104:3205-13

Bonneville M, Lang F. CD8: from coreceptor to comodulator. Nature Immunol 2002;3:12-4

Call ME, Wucherpfennig KW. Molecular mechanisms for the assembly of the T cell receptor-CD3 complex. Mol Immunol 2004;40:1295-305

Cerisano V, Aalto Y, Perdichizzi S, Bernard G, Manara MC,
Benini S, Cenacchi G, Preda P, Lattanzi G, Nagy B, Knuutila S, Colombo MP, Bernard A, Picci P, Scotlandi K. Molecular mechanisms of CD99-induced caspase-independent cell death and cell-cell adhesion in Ewing's sarcoma cells: actin and zyxin as key intracellular mediators. Oncogene 2004; 23:5664-74

Choi EY, Park WS, Jung KC, Kim SH, Kim YY, Lee WJ, Park $\mathrm{SH}$. Engagement of CD99 induces up-regulation of TCR and MHC class I and II molecules on the surface of human thymocytes. J Immunol 1998;161:749-54

Citovsky V, Lee LY, Vyas S, Glick E, Chen MH, Vainstein A, Gafni Y, Gelvin SB, Tzfira T. Subcellular localization of interacting proteins by bimolecular fluorescence complementation in planta. J Mol Biol 2006;362:1120-31

Dong G, Ni Z, Yao Y, Nie X, Sun Q. Wheat Dof transcription factor WPBF interacts with TaQM and activates transcription of an alpha-gliadin gene during wheat seed development. Plant Mol Biol 2007;63:73-84

Dworzak MN, Fritsch G, Buchinger P, Fleischer C, Printz D, Zellner A, Schollhammer A, Steiner G, Ambros PF, Gadner $\mathrm{H}$. Flow cytometric assessment of human MIC2 expression in bone marrow, thymus, and peripheral blood. Blood 1994;83:415-25

Fellinger EJ, Garin-Chesa P, Triche TJ, Huvos AG, Rettig WJ. Immunohistochemical analysis of Ewing's sarcoma cell surface antigen p30/32MIC2. Am J Pathol 1991;139:317-25

He JS, Ostergaard HL. CTLs contain and use intracellular stores of FasL distinct from cytolytic granules. J Immunol 2007;179:2339-48

Hu CD, Chinenov Y, Kerppola TK. Visualization of interactions among bZIP and Rel family proteins in living cells using bimolecular fluorescence complementation. Mol Cell 2002;9:789-98

Hu CD, Kerppola TK. Simultaneous visualization of multiple protein interactions in living cells using multicolor fluorescence complementation analysis. Nat Biotechnol 2003; 21:539-45

Kasinrerk W, Tokrasinwit N, Moonsom S, Stockinger H. CD99 monoclonal antibody induce homotypic adhesion of Jurkat cells through protein tyrosine kinase and protein kinase C-dependent pathway. Immunol Lett 2000;71:33-41

Kim SH, Choi EY, Shin YK, Kim TJ, Chung DH, Chang SI, Kim NK, Park SH. Generation of cells with Hodgkin's and ReedSternberg phenotype through downregulation of CD99 (Mic2). Blood 1998;92:4287-95

Kim SH, Shin YK, Lee IS, Bae YM, Sohn HW, Suh YH, Ree $\mathrm{HJ}$, Rowe M, Park SH. Viral latent membrane protein 1 (LMP-1)-induced CD99 down-regulation in B cells leads to the generation of cells with Hodgkin's and Reed-Sternberg phenotype. Blood 2000;95:294-300

Lee EJ, Lee HG, Park SH, Choi EY, Park SH. CD99 type II is a determining factor for the differentiation of primitive neuroectodermal cells. Exp Mol Med 2003a;35:438-47

Lee IS, Shin YK, Chung DH, Park SH. LMP1-induced downregulation of CD99 molecules in Hodgkin and ReedSternberg cells. Leuk Lymphoma 2001;42:587-94 
Lee IS, Kim SH, Song HG, Park SH. The molecular basis for the generation of Hodgkin and Reed-Sternberg cells in Hodgkin's lymphoma. Int J Hematol 2003b;77:330-5

Lumadue JA, Askin FB, Perlman EJ. MIC2 analysis of small cell carcinoma. Am J Clin Pathol 1994;102:692-4

Maekawa A, Schmidt B, Fazekas de St Groth B, Sanejouand YH, Hogg PJ. Evidence for a domain-swapped CD4 dimer as the coreceptor for binding to class II MHC. J Immunol 2006;176:6873-8

Oh KI, Kim BK, Ban YL, Choi EY, Jung KC, Lee IS, Park SH. CD99 activates $T$ cells via a costimulatory function that promotes raft association of TCR complex and tyrosine phosphorylation of TCR zeta. Exp Mol Med 2007;39:176-84

Park SH, Shin YK, Suh YH, Park WS, Ban YL, Choi HS, Park HJ, Jung KC. Rapid divergency of rodent CD99 orthologs: implications for the evolution of the pseudoautosomal region. Gene 2005;353:177-88

Petri B, Bixel MG. Molecular events during leukocyte diapedesis. FEBS J 2006;273:4399-407

Roopenian DC, Christianson GJ, Sproule TJ, Brown AC, Akilesh S, Jung N, Petkova S, Avanessian L, Choi EY, Shaffer DJ, Eden PA, Anderson CL. The MHC class I-like IgG receptor controls perinatal IgG transport, IgG homeostasis, and fate of IgG-Fc-coupled drugs. J Immunol 2003;170: 3528-33

Ross NL, Mavrogiannis LA, Sargent CA, Knight SJ, Wadekar $R$, DeLisi LE, Crow TJ. Quantitation of X-Y homologous genes in patients with schizophrenia by multiplex polymerase chain reaction. Psychiatr Genet 2003;13:115-9

Schenkel AR, Mamdouh Z, Chen X, Liebman RM, Muller WA. CD99 plays a major role in the migration of monocytes through endothelial junctions. Nat Immuol 2002;3:143-50

Shiratori I, Ogasawara K, Saito T, Lanier LL, Arase H. Activation of natural killer cells and dendritic cells upon recognition of a novel CD99-like ligand by paired immunoglobulin-like type 2 receptor. J Exp Med 2004;199:525-33

Shyu YJ, Liu H, Deng $X$, Hu CD. Identification of new fluorescent protein fragments for bimolecular fluorescence complementation analysis under physiological conditions. Biotechniques 2006;40:61-6
Smith MJ, Goodfellow PJ, Goodfellow PN. The genomic organisation of the human pseudoautosomal gene MIC2 and the detection of a related locus. Hum Mol Genet 1993;2: 417-22

Sohn HW, Choi EY, Kim SH, Lee IS, Chung DH, Sung UA, Hwang DH, Cho SS, Jun BH, Jang JJ, Ghi JG, Park SH. Engagement of CD99 induces apoptosis through a calcineurin-independent pathway in Ewing's sarcoma cells. Am J Pathol 1998;153:1937-45

Stomski FC, Sun Q, Bagley CJ, Woodcock J, Goodall G, Andrews RK, Berndt MC, Lopez AF. Human interleukin-3 (IL-3) induces disulfide-linked IL-3 receptor alpha- and beta-chain heterodimerization, which is required for receptor activation but not high-affinity binding. Mol Cell Biol 1996; 16:3035-46

Valk E, Leung R, Kang H, Kaneko K, Rudd CE, Schneider H. $T$ Toll receptor-interacting molecule acts as a chaperone to modulate surface expression of the CTLA-4 coreceptor. Immunity 2006;25:807-21

Wilson MD, Cheung J, Martindale DW, Scherer SW, Koop BF. Comparative analysis of the paired immunoglobulin-like receptor (PILR) locus in six mammalian genomes: duplication, conversion, and the birth of new genes. Physiol Genomics 2006;27:201-18

Yano A, Kodama Y, Koike A, Shinya T, Kim HJ, Matsumoto M, Ogita S, Wada Y, Ohad N, Sano H. Interaction between methyl CpG-binding protein and ran GTPase during cell division in tobacco cultured cells. Ann Bot 2006;98:1179-87

Yoon SS, Jung KI, Choi YL, Choi EY, Lee IS, Park SH, Kim TJ. Engagement of CD99 triggers the exocytic transport of ganglioside GM1 and the reorganization of actin cytoskeleton. FEBS Lett 2003;540:217-22

Zeng FY, Wess J. Identification and molecular characterization of $\mathrm{m} 3$ muscarinic receptor dimers. J Biol Chem 1999;274:19487-97

Zhu X, Peng J, Raychowdhury R, Nakajima A, Lencer WI, Blumberg RS. The heavy chain of neonatal Fc receptor for $\mathrm{lgG}$ is sequestered in endoplasmic reticulum by forming oligomers in the absence of beta2-microglobulin association. Biochem J 2002;367:703-14 